\section{IMPLEMENTATION OF LIFE SKILLS IN ORDER TO ADD FAMILY INCOME AND CONTRIBUTIONS TO EMPOWERMENT OF WOMEN}

\section{IMPLEMENTASI PEMBERIAN LIFE SKILLS DALAM RANGKA MENAMBAH PENDAPATAN KELUARGA DAN KONTRIBUSINYA TERHADAP PEMBERDAYAAN PEREMPUAN}

Jurnal Pendidikan Luar Sekolah

http://kolokium.ppj.unp.ac.id/

Jurusan Pendidikan Luar Sekolah

Fakultas Ilmu Pendidikan

Universitas Negeri Padang

Sumatera Barat, Indonesia

Volume 7, Nomor 2, Oktober 2019 DOI: $10.24036 /$ kolokium-pls.v7i2.354

\author{
Jalius',2, Vevi Sunarti', Zahratul Azizah', Reza Gusmanti ${ }^{1}$ \\ 1Jurusan Pendidikan Luar Sekolah Fakultas Ilmu Pendidikan Universitas Negeri Padang \\ 2Email: jalius_hr@fip.unp.ac.id
}

\begin{abstract}
Life skills education is a valuable and strategic investment in producing skilled and skilled Indonesian people in various fields according to the needs of the community and the world of work. This means that life skills are given to all elements of society, especially for women. Women as someone who has an important role in the family is the key to success in the existence of his family. Life skills education is provided in order to help increase family income, which in this case contributes to women's empowerment. Padang State University as one of the higher education institutions facilitates community service. The focus of community service that the writer adopts here is the empowerment of women through the provision of life skills in order to help increase family income. This service was carried out in Nagari Siguntur, Pesisir Selatan Regency. The number of subjects (training participants) is 15 women. The method used is lectures, workshops and training. Data collection techniques are observation (assessment process) and interviews. The data analysis technique used is descriptive analysis. The results of the implementation of the community empowerment program showed that (1) the number of participants who actively participated in women's empowerment activities through the provision of life skills was 15 people, (2) the training participants had knowledge and skills in making bross, and arranging flowers from used cloth, (3) the formation of a small-scale bross production group as souvenirs for parties and cloth flower displays.
\end{abstract}

Keywords: Women's Empowerment, Life Skills, Family Income

\begin{abstract}
ABSTRAK
Pendidikan kecakapan hidup (life skill) merupakan investasi yang sangat berharga dan strategis dalam menghasilkan manusia Indonesia yang terampil dan berkeahlian dalam berbagai bidang sesuai dengan kebutuhan masyarakat dan dunia kerja. Ini berarti bahwa life skills diberikan kepada seluruh elemen masyarakat, terutama bagi perempuan. Perempuan sebagai sosok yang memiliki peran penting dalam keluarga menjadi kunci keberhasilan dalam keberadaan keluarganya. Pemberian pendidikan kecakapan hidup dilakukan dalam rangka membantu menambah pendapatan keluarga yang dalam hal ini
\end{abstract}


berkontribusi terhadap pemberdayaan perempuan. Universitas Negeri Padang sebagai salah satu lembaga pendidikan tinggi memfasilitasi dalam bentuk pengabdian masyarakat. Fokus pengabdian masyarakat yang penulis angkat di sini adalah pemberdayaan perempuan melalui pemberian life skills dalam rangka membantu menambah pendapatan keluarga. Kegiatan pengabdian ini dilakukan di Nagari Siguntur Kabupaten Pesisir Selatan. Jumlah subjek (peserta pelatihan) sebanyak 15 orang perempuan. Metode yang digunakan adalah ceramah, workshop dan pelatihan. Teknik pengumpulan data yaitu pengamatan (penilaian proses) dan wawancara. Teknik analisis data yang digunakan adalah analisis deskriptif. Hasil pelaksanaan program pemberdayaan masyarakat menunjukkan bahwa (1) jumlah peserta yang berpartisifasi aktif dalam kegiatan pemberdayaan perempuan melalui pemberian life skill sebanyak 15 orang, (2) peserta pelatihan telah memiliki pengetahuan dan keterampilan dalam membuat bross, dan merangkai bunga dari kain bekas, (3) terbentuknya kelompok usaha kecil produksi bross sebagai cindra mata untuk pesta dan pajangan bunga dari kain.

Kata Kunci: Pemberdayaan Perempuan, Life Skills, Pendapatan Keluarga

\section{PENDAHULUAN}

Informasi terus berkembang seraya berkembangnya pendidikan dan teknologi. Informasi sudah menjadi kebutuhan penting masyarakat. Media yang disediakan pun terus berkembang untuk memudahkan masyarakat dalam mendapatkan informasi dan untuk mendapatkan informasi tersebut masyarakat harus melek informasi (Damanik, 2012; Harnita, 2017; Subarjo, 2017). Kemajuan teknologi dan komunikasi yang begitu pesat membuat kebutuhan akan informasi bagi masyarakat juga meningkat (Budiman, 2017). Masyarakat yang kaya dengan informasi dia akan maju dan berkembang sesuai dengan perkembangan ilmu pengetahuan itu sendiri, sebaliknya masyarakat yang tertinggal dalam informasi dia juga akan tercecer dari perkembangan dan kemajuan (Ngafifi, 2014). Kebutuhan ini bukan hanya merupakan kebutuhan masyarakat perkotaan saja namun masyarakat pedesaan juga sangat membutuhkannnya.

Pendidikan menurut UU No 20 Tahun 2003 (dalam Mirnawat, 2017)iadalah usaha sadar dan terencana untuk mewujudkan suasana belajar dan proses pembelajaran agar peserta didik secara aktif mengembangkan potensi dirinya untuk memiliki kekuatan spiritual keagamaan, pengendalian diri, kecerdasan, akhlak mulia, serta keterampilan yang diperlukan dirinya, masyarakat, bangsa dan negara. Pendidikan sengaja dirancang untuk membekali peserta didik dengan kecakapan hidup. Pendidikan bermaksud membantu peserta didik untuk menumbuh kembangkan potensi-potensi kemanusiaan (Saripah \& Shantini, 2016). Pendidikan yang pada hakekatnya hendak memanusiakan manusia, namun pada kenyataannya tidaklah demikian. Proses pembangunan dan industrialisasi yang terjadi secara cepat terkadang menjadikan manusia tidak lagi bersifat manusiawi, dan saat inilah pendidikan orang dewasa diperlukan (Finger, 2004).

Pada prinsipnya pendidikan merupakan upaya untuk memanusiakan manusia (humanisasi). Untuk itu pendidikan harus dapat mengembangkan potensi dasar peserta didik agar berani menghadapi problema yang dihadapi tanpa rasa tertekan, mau, mampu, dan senang meningkatkan fitrahnya sebagai khalifah di muka bumi. Pendidikan juga diharapkan mampu mendorong peserta didik untuk memelihara diri sendiri, sambil meningkakan hubungan dengan Tuhan YME, masyarakat dan lingkungannya. Sangat diperlukan pendidikan yang sengaja dirancang untuk membekali peserta didik dengan 
kecakapan hidup dan kehidupan yang secara integratif memadukan potensi generik dan spesifik guna memecahkan dan mengatasi problematika kehidupan.

Dalam kehidupan sehari-hari, manusai akan selalu dihadapkan pada problema hidup yang harus dipecahkan dengan mengunakan berbagai sarana dan situasi yang dapat dimanfaatkan. Kemampuan seperti itulah yang merupakan salah satu inti kecakapan hidup. Artinya kecakapan yang selalu diperlukan seseorang dimanapun dia berada ketika mengarungi kehidupan, baik bekerja atau tidak bekerja dan apapun profesinya. Pendidikan perlu berperan aktif membantu mengatasi pengangguran. Perlu difikirkan bagaimana pendidikan dapat berperan mengubah manusia-beban menjadi manusia-produktif, bekal apa yang perlu diberikan kepada peserta didik agar dapat memasuki dunia kerja.

Peningkatan mutu pendidikan Indonesia merupakan suatu keharusan dan menjadi komitmen untuk meningkatkan mutu sumber daya manusia. Mutu pendidikan di Indonesia belum bisa dikatakan mengembirakan karena angka pengangguran masih terus meningkat seiring dengan perkembangan zaman sekarang ini. Tentunya peran pendidikan sangat diharapkan dalam membantu mengatasi pengganguran tersebut. Pendidikan sejatinya dapat berperan mengubah manusia yang awalnya beban menjadi produktif, dengan diberikan bekal yang dapat dengan segera memasuki dunia kerja, mampu menghidupi dirinya dan bisa menghidupi keluarganya.

Perkembangan teknologi industri 4.0 dewasa ini, mau tidak mau akan memunculkan persaingan yang cukup ketat dalam kerja. Artinya, untuk menjadi tenaga kerja, seseorang harus mampu bersaing secara terbuka dengan tenaga kerja asing lainnya. Oleh karena itu pendidikan dalam hal ini berperan aktif dalam mempersiapkan calon tenaga kerja yang mampu bersaing dengan yang lainnya. Pendidikan hendaknya dapat membekali diri seseorang dengan kecakapan hidup dalam arti seseorang itu berani menghadapi segala persoalan hidup, kemudian mampu memecahkannya dan mencari solusi dari permasalahan yang diharapinya tanpa ada rasa beban dan rasa tertekan, sehingga mampu menciptakan peluang pekerjaan yang diinginkan.

\section{METODE}

Metode yang digunakan dalam kegiatan pengabdian masyarakat ini adalah metode ceramah, workshop dan pelatihan. Kegiatan pengabdian masyarakat memberikan beberapa materi berupa pengetahuan tentang peran perempuan dalam kelurga dan pengetahuan tentang bagaimana mengembangkan jiwa wirausaha. materi disampaikan oleh narasumber kepada sasaran yakni perempuan muda, yang untuk selanjutnya materi tersebut dilanjutkan dengan workshop dan latihan guna mempraktekkan langsung keterampilan yang diberikan. Teknik pengumpulan data yaitu pengamatan (penilaian proses) dan wawancara. Teknik analisis data yang digunakan adalah analisis deskriptif.

\section{HASIL PENELITIAN DAN PEMBAHASAN}

Life skills diberikan kepada seluruh elemen masyarakat, terutama bagi perempuan. Perempuan sebagai sosok yang memiliki peran penting dalam keluarga menjadi kunci keberhasilan dalam keberadaan keluarganya. Pemberian pendidikan kecakapan hidup dilakukan dalam rangka membantu menambah pendapatan keluarga yang dalam hal ini berkontribusi terhadap pemberdayaan perempuan. 
Perempuan dalam keluarga memiliki multi peran. salah satu peran sebagai pendamping suami dalam rangka membantu pendapatan suami. Perkembangan teknologi yang semakin maju dewasa ini memunculkan kesadaran bagi perempuan. Perempuan memiliki peran penting dalam pembangunan nasional. Dalam meningkatkan peran tersebut perlu upaya dalam meningkatkan kualitas perempuan yakni malalui pemberdayaan. Nasdian (dalam Saugi \& Sumarno, 2015) menyatakan bahwa pemberdayaan (empowerment) merupakan suatu proses yang ditujukan untuk membantu masyarakat memperoleh daya (kuasa) untuk mengambil keputusan dan menentukan tindakan yang akan ia lakukan, termasuk mengurangi efek hambatan pribadi dan sosial dalam melakukan tindakan. Ife \& Tesoriero (dalam Saugi \& Sumarno, 2015) menjelaskan bahwa "pemberdayaan bertujuan meningkatkan keberdayaan dari mereka yang dirugikan (the disadvantaged)".

Menurut (Badan Pusat Statistik, 2013)iijumlah penduduk Indonesia akan mencapai 269,6 juta jiwa pada 2020. Jumlah tersebut terdiri atas kategori usia belum produkftif (0-14 tahun) sebanyak 66,07 juta jiwa, usia produktif (15-64 tahun) 185,34 juta jiwa, dan usia sudah tidak produktif (65+ tahun) 18,2 juta jiwa. Jumlah penduduk Indonesia diproyeksikan terus bertambah menjadi 318,96 juta pada 2045. Berdasarkan data tersebut, Indonesia akan mengalami masa bonus demografi hingga 2045. Di mana jumlah penduduk usia produktif lebih banyak dibandingkan penduduk tidak produkif (belum produktif dan sudah tidak produktif). Jumlah usia produktif pada 2020 mencapai $68,75 \%$ dari total populasi. Melimpahnya sumber daya manusia usia produktif ini hendaknya dapat dimanfaatkan dengan peningkatan kualitas, baik pendidikan maupun keterampilan guna menyongsong era industri 4.0. Dengan jumlah penduduk usia produktif yang lebih besar tersebut maka angka ketergantungan penduduk (dependency ratio) Indonesia sebesar 45,46. Artinya, setiap 100 penduduk usia produktif memiliki tanggungan 46 jiwa penduduk usia tidak produktif.

Seorang perempuan dalam keluarga berperan sebagai ibu rumah tangga memiliki berbagai masalah yang harus dipecahkan, di mana diperlukan kecakapan hidup/life skill. Pemberian life skill kepada permpuan memberi implikasi luas yang tidak hanya pada perubahan pola kemampuan belajar perempuan muda dalam hal pelatihan, pengetahuan dan keterampilan hidup yang dibutuhkan sehari-hari, namun juga mampu mempengaruhi konsep perempuan sebagai pendamping suami yang bisa membantu menambah pendapatan keluarganya. Indikator keberhasilan pelatihan diantaranya adalah bertambahnya pengetahuan dan keterampilan warga, serta diperolehnya pendapatan hasil usaha penjualan produk (Wildan dalam Saktya, Hindiarto, \& Setyorini, 2015).

Dalam memberikan kecakapan hidup kepada perempuan sebagai pribadi orang dewasa, tentunya harus memperhatikan faktor yang dapat mempengaruhi proses pembelajaran orang dewasa. Faktor yang mempengaruhi pembelajaran orang dewasa yaitu faktor internal dan faktor eksternal (Zainuddin, 2014). Faktor internal disini adalah segala faktor yang bersumber dari dalam diri warga belajar, dan faktor eksternal adalah faktor yang dari luar diri warga belajar.

Finger (2004) mengatakan bahwa pembelajaran dilihat dalam perspektif yang diharapkan memberi kontribusi terhadap perkembangan ekonomi dan peluang seseorang untuk berpartisipasi dalam pasar buruh atau lebih umumnya kemampuan seseorang untuk bertahan hidup dalam ekonomi global. Membelajarkan perempuan memberi kontribusi dalam membantu menambah penghasilan keluarganya. Hal ini diasumsikan bahwa jika perempuan dibekali pengetahuan, keterampilan yang semuanya dalam wujud kecakapan hidup, kedepannya akan bernilai guna dalam menompang kehidupan ekonominya sehingga dapat menambah penghasilan untuk keluarganya. 
Menurut Rachman (dalam Wahyuni \& Indrasari, 2017), diperlukan pola pendidikan yang dengan sengaja dirancang untuk membekali peserta didik dengan kecakapan hidup, yang secara integratif memadukan kecakapan generik dan spesifik guna memecahkan dan mengatasi problematika kehidupan. Perempuan dengan diberikan kecakapan hidup berupa keterampilan keterampilan yang bisa dia gunakan dalam mencari penghasilan sejatinya akan mengatasi persoalan-persoalan kehidupan seperti perekonomian keluarga. Sehingga pada akhirnya perempuan akan berdaya, bernilai guna dalam kehidupan masyarakat dan memiliki harga diri yang layak untuk kehidupannya.

\section{KESIMPULAN}

Pemberian life skills kepada perempuan muda memberikan implikasi luas yang tidak hanya pada perubahan pola kemampuan belajar perempuan muda dalam hal pengetahuan dan keterampilan hidup yang dibutuhkan sehari-hari, namun juga mampu mempengaruhi konsep perempuan sebagai pendamping suami yang bisa membantu menambah pendapatan keluarganya. Pengetahuan dan keterampilan yang telah diperoleh perempuan muda pada akhirnya diharapkan mereka mampu berdikari, membuka usaha sendiri, berwirausaha dengan modal pengetahuan dan keterampilan yang sudah diberikan, dan ini tentunya perlu didukung pula dari pihak-pihak pemangku kebijakan daerah setempat dalam hal bantuan modal usaha.

\section{DAFTAR RUJUKAN}

Ananto, P., Astuti, R., \& Ariani. (2007). Pendidikan Kecakapan Hidup untuk Mencegah HIV/AIDS. Jakarta: Kepala Pusat Pengembangan Kualitas Jasmani, Departemen Pendidikan Nasional.

Anwar. (2004). Pendidikan Kecakapan Hidup (Life Skills Education). Bandung: Alfabeta.

Anwara, K., \& Setiawan, H. (2018). Analisis Perbandingan Pendapatan Buruh Harian Tetap dengan Buruh Harian Lepas dan Pengaruhnya terhadap Kesejahteraan Keluarga Buruh Perkebunan Kelapa Sawit di Kota Subulussalam. Jurnal Ekonomi Pertanian Unimal, 1(1), 73-81.

Badan Pusat Statistik. (2013). Proyeksi Penduduk Indonesia 2010-2035. Jakarta: Badan Pusat Statistik. Retrieved from https://www.bappenas.go.id/files/5413/9148/4109/Proyeksi_Penduduk_Indonesi a_2010-2035.pdf

Dimas Abu Farhan. (2017). Pemberdayaan Kaum Perempuan Guna Meningkatkan Pendapatan Keluarga dalam Perspektif Ekonomi Islam (Study pada Kelompok. Wanita Tani Sekarmulia, Desa Astomulyo, Kecamatan Punggur, Kabupaten Lampung Tengab). Universitas Islam Negeri Raden Intan Lampung.

Fadjar, M. (2002). Paparan Seputar Langkah-langkah Menuju Tercapainya Sasaran Pembangunan Pendidikan (Disampaikan dalam Sidang Kabinet). Jakarta: Departemen Pendidikan Nasional.

Fasa, R. Z. M. (2019). Resiliensi Keluarga Korban Bencana Longsor di Kecamatan Cimeyan Kabupaten Bandung. Jurnal Mimbar Kesejabteraan Sosial, 2, 1-11.

Finger, M. (2004). Pendidikan Orang Dewasa. Yogyakarta: Pustaka Kendi.

Hanum, S. L. (2017). Peran Ibu Rumah Tangga dalam Membangun Kesejahteraan Keluarga. Academica, 1(2).

Kurniasari, A. F. (2016). Pengaruh Terpaan Iklan Layanan Masyarakat, Penggunaan Media Sosial Facebook, Dukungan Keluarga, Dukungan Lingkungan Kerja terhadap 
Tingkat Keberhasilan Ibu Bekerja Memberi Asi Ekslusif. Jurnal Interaksi, 5(2), 146158.

Mirnawat, L. B. (2017). Pengaruh Model Pembelajaran Kooperatif Tipe Group Investigation terhadap Kreativitas Mahasiswa Semester 1 PGSD UM Surabaya pada Mata Kuliah Pengantar Manajemen Pendidikan. Pedagogia:Jurnal Pendidikan, 6(1), 84-97.

Saktya, O. P. D., Hindiarto, F., \& Setyorini, T. D. (2015). Pengaruh Pelatihan Keterampilan Menjual terhadap Peningkatan Kinerja Penjualan Staf Markeeting PT.BPR Mekar Nugraha. Kajian Ilmiah Psikologi, 1(4), 72-80. Retrieved from http://journal.unika.ac.id/index.php/pre/article/viewFile/508/430

Saripah, I., \& Shantini, Y. (2016). Implementasi Model Pembelajaran Mandiri Program Pendidikan Kecakapan Hidup Perempuan. Jurnal Pendidikan Dan Pemberdayaan Masyarakat, 3(2), 176-186.

Saugi, W., \& Sumarno. (2015). Pemberdayaan Perempuan Melalui Pelatihan Pengelolaan Bahan Pangan Lokal. Jurnal Pendidikan Dan Pemberdayaan Masyarakat, 2(2), 226-238.

Setiorini, D., \& Munoto. (2016). Pengembangan Perangkat Pembelajaran Berorientasi Kecakapan Hidup (life-Skill) dengan Menerapkan Model Pembelajaran Kooperatif Tipe Student Teams Achievement Divisions (STAD) untuk Meningkatkan Hasil Belajar pada Mata Pelajaran Instalasi Penerangan Listrik. Jurnal Pendidikan Teknik. Elektro, 5(2), 445-452.

Wahyuni, S., \& Indrasari, D. Y. (2017). Implementasi Pendidikan Life Skill di SMK Negeri 1 Bondowoso (Implementation of Life Skills Education in SMK Negeri 1 Bondowoso). Jurnal Edukasi, 4(1), 24-29.

Zainuddin. (2014). Implementasi Andragogi di Pondok Pesantren Mahasiswa Al- Hikmah Malang. Universitas Islam Negeri Maulana Malik Ibrahim Malang. Retrieved from http:/ / etheses.uin-malang.ac.id/8012/1/12770023.pdf 